\title{
Symbiotic Gels: Alternative in Renal Insufficiency
}

\author{
Cituk-Cutz GJ ${ }^{1}$, Pech-Canul ER ${ }^{1}$, Tuyub-Alonzo \\ $\mathbf{R}^{1}$, J iménez-Báez $\mathbf{M V}^{2 *}$, Ureña-Bogarín $\mathrm{EL}^{2}$, \\ Sandoval-J urado $\mathrm{L}^{2}$ and Chávez-Hernández $\mathrm{MM}^{2}$ \\ ${ }^{1}$ Student of the Degree in Medicine, Division of Health \\ Sciences University of Quintana Roo, General Hospital \\ Clinical Cycles No. 17, Mexican Institute of Social \\ Security, Cancun, Quintana Roo, Mexico \\ ${ }^{2}$ Mexican Social Security Institute (IMSS), State \\ Delegation in Quintana Roo, Clinical Research Group of \\ IMSS in Quintana Roo (GRICIQ), Mexico \\ *Corresponding author: J iménez-Báez MV, J efatura \\ de Servicios Prestaciones Médicos Av. Politécnico \\ Nacional s/n SMZ 510, CP. 77509 Cancún, Quintana Roo, \\ Mexico
}

Received: August 08, 2017; Accepted: August 31, 2017; Published: September 08, 2017

\section{Abstract}

Probiotics are microorganisms that provide a positive effect on the host where Lactobacillus and Bifidobacteruim are the most frequent species in this group; on the other hand prebiotics are substances that provide a selective stimulation of growth to species beneficial to humans such as those mentioned above, where inulin or oligofructose are the most representative substances in this category. The intestinal flora represents a great variety of microorganisms such as Bacteroides, Faecalibacterium, Bifidobacterium among others, maintaining a homeostasis in its environment, however in patients with chronic renal failure (CKD) show an increase in the intestinal level of aerobic bacteria such as Firmicutes, Actinobacteria and Proteobacteria resulting in an increase of metabolites such as phenols, indoles and amines that contribute to uremic toxicity. It is known that the use of probiotics and prebiotics have many applications in the medical field, from cardiovascular diseases, diarrhea, allergies, Helicobacter pylori erradication, nephropathies to use in cancer patients. The increase in the number of patients with chronic renal failure) and the mechanisms of action by these microorganisms could represent an alternative in these patients. However, the scientific evidence in this area is limited, which represents an area of opportunity. Through the analysis, we intend to present scientific evidence in the use of probiotics (lactobacillus rhamnosus NH001, Bifidobacteriumlactis Bi07) and prebiotics (blue agave inulin) as an alternative treatment in patients with renal failure for the significant decrease in toxin levels.

Keywords: Probiotics; Urea; Lactobacillus rhamnosus; Bifidobacterium

\section{Introduction}

Between 2011-2012, there were a total of 54.6 - 56 million deaths worldwide, of which 38 million were for noncommunicable diseases such as cardiovascular diseases, cancer, chronic respiratory diseases and diabetes, about 29 million People with this characteristic required palliative care where renal failure represents $2 \%$ of the total number of patients [1,2].

The increase in the prevalence of chronic renal failure worldwide is $6-10 \%$ of the adult population can be classified in different stages, due to factors such as progressive aging of the population, diabetes mellitus, hypertension and obesity that condition an increase in the risk of cardiovascular events among others [3-5]. Currently, the IRC represents a public health problem the impact in economic terms generates a large consumption of inputs and an adequate coordination among health professionals who are involved in medical care [6].

Due to the current panorama of patients with CRF, new alternatives have been developed in the medical area in order to improve the quality of life of patients; This is how a new concept called "functional food", defined as that product, modified food or food ingredient that provides health benefits, arises; This concept makes its appearance from the works of Metchnikoff in century XX who suggests that the lactic bacteria had a positive impact on the human beings [7].

The positive impact of these microorganisms on the guests, open a new path in the medical field as an alternative in pathologies such as cardiovascular diseases, diarrhea, allergies, Helicobacter pylori eradication, reduction of cancer risk, osteoporosis, nephropathy, hepatic encephalopathy, among others tested with scientific studies on the benefits of probiotics. Renal insufficiency is a poorly studied field and represents a promising alternative [8-10].

The purpose of this article is to know the scientific evidence on the use of probiotics as an alternative treatment in patients with renal insufficiency for the significant reduction of levels of toxins (urea, ammonium) with the use of lactobacillus rhamnosus NH001, Bifidobacteriumlactis Bi07, and inulin Blue agave through scientific evidence level II-IV.

\section{Probiotics and Prebiotics}

Probiotics are living microorganisms that give a positive impact to the health of the host, where species such as Lactobacillus and Bifidobacterium are the species that most frequently for their characteristics among which we find resistance to gastric acid, bile salts, pancreatic enzymes and by the Adherence to the colon mucosa $[11,12]$.

Prebiotics are substances that nourish groups of microorganisms selected in the gut promotes the growth of bacteria that favorably impact the host, inulin one of the most commonly used prebiotics, in vitro tests have been found to significantly increase lactobacilli and bifidobacteria; In a randomized double-blind placebo-controlled study with 29 patients it was observed that supplementation 7.5 grams of agave inulin for 21 days had a favorable impact of 3 to 4 times more compared to the control in Actinobacteria and Bifidobacterium [8,13-15].

\section{Normal Intestinal Flora}

The microbial flora or microflora refers to the great variety of
J Fam Med - Volume 4 Issue 5 - 2017

ISSN : 2380-0658 | www.austinpublishing group.com

Jiménez-Báez et al. (C) All rights are reserved
Citation: Cituk-Cutz GJ, Pech-Canul ER, Tuyub-Alonzo R, Jiménez-Báez MV, Ureña-Bogarín EL, SandovalJurado L, et al. Symbiotic Gels: Alternative in Renal Insufficiency. J Fam Med. 2017; 4(5): 1126. 
Table 1: Principal mechanisms of action of probiotics.

\begin{tabular}{|c|c|c|}
\hline Probiotics & Action & Mechanism \\
\hline 1. L.Rhammnosus GG & $\begin{array}{l}\text { Prevents colonization of pathogenic } \\
\text { microorganisms }\end{array}$ & Blocks adhesion receptors and competes for nutrients \\
\hline 2. L.Rhammnosus GG & Antimicrobial activity & Production of substances with antimicrobial action \\
\hline $\begin{array}{l}\text { 3. L.Rhammnosus GG \& } \\
\text { Bifidobacterium }\end{array}$ & Immunomodulatory & Regulates the humoral and cellular immune response \\
\hline 4. Bifidobacterium & Enzymatic activity & $\begin{array}{c}\text { Decreases the activity of enzymes associated with the synthesis of lactose, } \\
\text { pro-carcinogens }\end{array}$ \\
\hline
\end{tabular}

aerobic and anaerobic microorganisms that inhabit both internal and external surfaces of humans, however, that environment does not remain constant throughout life due to certain changes in adaptation being exposed to variables such as race, hygiene, states of stress and age [16].

In the adult individual, the gastrointestinal tract reaches an area of 300 to 400 square meters, so that it is formed of structures and specific functions in charge of the analytical and biochemical recognition of the substances that transit through the digestive tract [17]. In the newborn, its intestinal flora is found to be sterile and colonized by bacteria such as E. colli and streptococci, being fed with breast milk significantly increases the number of bacteria such as bifidobacteria was approximately at the age of two years the flora of the child becomes similar to that which predominates in the adult $[18,19]$.

Normally the small intestine is sterile, unlike the large intestine in which a large number of different bacteria are found, such as Bacteroides, Faecalibacterium, Bifidobacterium [20,21]. Most bacterial species are strictly anaerobic, therefore the bacterial density increases progressively along the intestinal length reaching its maximum in the colon, biotransforming the conjugated bile acids which are molecules involved in the modulation of fat metabolism or glucose [22,23].

The intestinal flora maintains several functions in the organism maintaining a homeostasis as a protective effect against the proliferation or infection of pathogenic bacteria, metabolic functions that consist of fermentation, putrefaction, synthesis of vitamins; The barrier effect by competition for nutrients and space, production of substances that lower $\mathrm{PH}$, stimulation of the host immune system and control of proliferation and differentiation of epithelial cells $[24,25]$.

\section{Alterations in the intestinal flora in CRF}

Uremic toxins originating from intestinal microbial metabolism may contribute to impaired renal function, cardiovascular calcification, metabolic bone disease, and mortality in CRF patients [26]. It is believed that many factors unrelated and related to dialysis may contribute to the inflammatory condition in CRF, even in the absence of an infectious process, the typical inflammatory state of the disease could be activated and/or enhanced by the passage of molecules and toxins Pro-inflammatory cells from the intestine to the bloodstream a phenomenon called bacterial translocation, where urease-producing microbial families such as Alteromonadacea, Cellulomonadacea, Clostridiacea [22]. microorganisms such as Escherichia Coli metabolize tryptophan producing indole which is subsequently absorbed and is metabolized in the liver to indoxyl sulphate [27], just as when carbohydrate concentrations are low, the amino acids can be subjected to fermentation, and produce Short chain fatty acids and toxins: ammonia, thiols, phenols, and indoles [28] all these phenomena increase uremic toxicity and intestinal barrier dysfunction [29,30].

Patients with CKD have different flora than normal flora, as aerobic bacteria such as Firmicutes, Actinobacteria, and Proteobacteria have been shown to be intestinal, and a smaller number of anaerobic bacteria, such as Sutterellaceae, Bacteroidaceae, and Lactobacillaceae, have been observed. Increased urea concentrations, and consequently an increase in $\mathrm{pH}$, which promotes the growth of aerobic bacteria in the gastrointestinal tract and the subsequent production of uremic toxins, leading to a thickening of the walls and infiltration of leukocytes in the lamina propria of tissues such as the stomach, jejunum, and ileum leading to microbial dysbiosis [28,31].

It has recently been shown that the renal toxicity of the intestinal microbiota could be mediated by the biotransformation of melamine to cyanuric acid. The precursors of uremic toxins are generated by fermentation in the TGI of amino acids such as phenylalanine, tyrosine, and tryptophan to generate p-cresol, phenol, and indole. These precursors are conjugated by passage through the intestinal wall and/or in the liver resulting in retention of circulating uremic solutes and/or toxins of p-cresyl sulfate, glucuronide p-cresyl, phenyl sulfate, phenyl glucuronide, sulfate Indoxyl and indoxyl glucuronide. The biological impact of these molecules induces proinflammatory responses, leukocyte stimulation, and endothelial dysfunction [32].

\section{Effects, Function, and Mechanism of Action of Probiotics}

Probiotics provide beneficial effects for the development of microbial flora in the intestinal flora, these effects achieved through antagonism preventing the multiplication of pathogens and production of toxins that preclude its pathogenic action in addition to governing an immune response through dendritic cell activity and natural killer cell and cytokine production $[33,34]$.

Among the characteristics of these microorganisms to fulfill their functions, probiotics must be normal inhabitants of the normal human intestine, not be pathogenic or toxicogenic, survive the acidic environment of the stomach and the effect of bile in the duodenum, as well as, capacity of adhesion to epithelial cells, adapting to the intestinal microbiota without displacing the existing native microbiota, producing antimicrobial substances and being able to positively enhance immune functions and metabolic activities $[35,36]$.

In renal disease there are high concentrations of urea [37] because there is an increase in $\mathrm{pH}$, which leads to the growth of aerobic bacteria in the gastrointestinal tract, in the case of Bifidobacterium, increases carbohydrates in a way that occurs Acetic acid and lactic acid to acidify the intestine, preventing aerobic pathogenic microorganisms from growing and reproducing, helping the intestinal flora with the 
decrease of bacteria producing uremic toxins [38] (Table 1).

\section{Effects, Function, and Mechanism of Action of Prebiotics}

A prebiotic is a nondigestible food ingredient (by the host), which has a beneficial effect through its selective stimulation of the growth or activity of one or a limited number of bacteria in the colon. Preliminary evidence indicates that inulin enriched with prebiotic oligofructose ( $\mathrm{p}$-inulin) promotes the growth of Bifidobacterium species, mediates weight loss, reduces inflammation, and improves metabolic function $[39,40]$.

Prebiotics are generally polymers consisting of 4 to 10 units of monomeric hexose, which provide selective stimulation of the growth or activity of beneficial native bacteria and because of their characteristics are not digested by small intestinal and pancreatic enzymes arriving unmodified into the colon $[40,41]$.

Supplementation with probiotics may alter the microbiota in the intestine of patients with CRF and is likely to increase saccharolytic activity by promoting a greater number of beneficial byproducts for the host, decreasing proteolytic activity by decreasing uremic solute production and intestinal inflammation, Preventing bacterial translocation and disruption of intestinal transport systems; Other effects attributed to probiotics are the ability to increase transit time, increase fecal weight with fewer side effects and increase the quality of life of patients [42].

Inulin has a linear chain bound by Beta bonds, important for being resistant to the enzymatic hydrolysis of human gastrointestinal, and the degree of polymerization of 11 to 65 units of fructose with a terminal glucose; Its use has demonstrated a greater degree of fermentation that produces FOS fructooligosaccharides polymerization, in addition, that it is associated with down-regulation of the production of IL- 6 and IFN-gamma. Nowadays one of the ways to increase the number of beneficial intestinal microorganisms is the use of prebiotic ingredients and to be able to generate the bifidogenic effect it is necessary that the prebiotic culture count in the colon is greater than or equal to 106 UFCG- 1 of fecal material [43].

Aliasgharzadeh et al. showed that supplementation with oligofructose-enriched inulin for 8 weeks in diabetic patients significantly decreased body weight, body mass index, fasting plasma glucose, fasting plasma glucose, $\mathrm{HbA1c}$, TC (total cholesterol), LDL-c , TC (total cholesterol) / HDL-c ratio, LDL-c / HDL-c ratio, LDL-c / HDL-c ratio and MDA (malondialdehyde), however, we could find no significant effect on TG (triglycerides), SOD (superoxide dismutase), GSH-Px (glutathione peroxidase) and catalase compared to the placebo group [44-51].

\section{Conclusions}

It is evident that the number of patients with CRF in stages prior to dialysis is worrisome, however, the knowledge of the pathophysiological mechanism regarding the damage caused by the increase of uremic toxins such as urea, thiols, phenols and indoles in the intestinal flora of these patients Provides us with new alternatives to reduce the time in which a patient arrives at that condition; It has been known for some time that the use of probiotics and prebiotics in the human being have a favorable impact and today it emerges as a promising and safe therapy in different clinical scenarios, nevertheless although there are investigations about the use in diverse pathologies The use of these microorganisms in CRF is limited, although we know what the mechanism of action in binomial of these microorganisms decreasing the levels of urea and contributing to the decrease of micro inflammation, represents a new field of study with the need of the elaboration Of studies focused on this area with a greater number of patients in order to make clinical recommendations based on evidence regarding the dosing of colony forming units providing a new alternative in terms of therapeutic management in patients with CRF.

\section{References}

1. World Health Organization. Global status report on noncommunicable diseases 2014. Geneva: 2014.

2. Connor, Sepulveda Bermedo MC. Global Atlas of Palliative Care at the End of Life. WHO, Worldwide Palliative Care Alliance; 2014.

3. Cases Amenósa A, González-Juanatey J, Conthe Gutiérrez P, Matalí Gilarranz A, Garrido Costae C. Prevalencia de insuficiencia renal crónica en pacientes de alto. Revista Española de Cardiología. 2010; 63: 225-228.

4. Gansevoort RT, Correa-Rotte R, Hemmelgam B. Chronic kidney disease and cardiovascular risk: epidemiology, mechanism and prevention. Lancet. 2013; 382: 339-352.

5. Jha V, Garcia-Garcia G, Iseki K. Chronic kidney disease: global dimension dimension. Lancet. 2013; 382: 260-272.

6. Gómez-Huelgas R, Martínez-Castelao A, Artola S, Górriz J, Menéndez E. Documento de Consenso sobre el tratamiento de la diabetes tipo 2 en el paciente con enfermedad renal crónica. Nefrología. 2014; 34.

7. Castro Á, De Rovetto C. Probióticos: utilidad clínica. Colombia Médica. 2006; 37.

8. Olveira Fuster G, González-Molero I. Probióticos y prebióticos en la práctica clínica. Nutrición Hospitalaria. 2007; 22.

9. Taibi A, Comelli E. Practical approaches to probiotics use. Applied Physiology, Nutrition, and Metabolism. 2014; 39: 980-986.

10. Dan WT, Greer R. Clinical Report-Probiotics and Prebiotics in Pediatrics. Pediatrics. 2010; 126

11. Soccol R, Porto de Souza Vandenberghe L, Rigon Spier, Pedroni Medeiros1 A, Tiemi Yamaguishi C, De Dea Lindner J, et al. The Potential of Probiotics: A Review. Food Technol. Biotechnol. 2010; 48: 413-434.

12. Mugambi MN, Young T, Blaauw R. Application of evidence on probiotics, prebiotics. BMC Research Notes. 2014; 7: 754.

13. World Gastroenterology Organisation. World Gastroenterology Organisation. 2011.

14. Gibson R, Scott P, Rastal A, Tuohy M, Hotchkiss A, Dubert-Ferrandon A, et al. Dietary prebiotics: current status and new definition. Food Science and Technology Bulletin: Functional Foods. 2010; 7.

15. Holscher HD, Bauer L, Gourineni V, Pelkman C, Fahey C, Swanson KS Agave Inulin Supplementation Affects the Fecal Microbiota of Healthy Adults Participating in a Randomized, Double-Blind, Placebo-Controlled, Crossover Trial. The Journal of Nutrition. 2015; 145: 2025-2032.

16. Garza Gisholt AC, Miranda Alatriste PV, Espinosa Cuevas M. Utilidad de los probióticos en la enfermedad renal: Nuevas aplicaciones. Nutrición Clínica. 2008. 11.

17. Guarner F. Papel de la flora intestinal en la salud y en la enfermedad. Nutrición Hospitalaria. 2007; 22.

18. Gill H, Garner F. Probiotics, and human health: a clinical perspective. Postgrad Med J. 2004; 80: 516-526.

19. Isolauri E. Probiotics in human disease. The American Journal of Clinical 
Nutrition. 2001; 73: 1142S-1146S

20. García de Lorenzo A. Importancia clínica de la translocación bacteriana. Nutrición Hospitalaria. 2007.

21. Robles Alonso V, Guarner F. Progreso en el conocimiento de la microbiota intestinal humana. Nutrición clinica. 2013; 28.

22. Sabatino, Regolisti G, Brusasco I, Cabassi A, Morabito S, Fiaccadori E. Alterations of intestinal barrier and microbiota in chronic kidney disease. Nephrology Dialysis Transplantation. 2015; 30: 924-933.

23. Cummings J, Macfarlane G. Role of intestinal bacteria in nutrient metabolism JPEN J Parenter Enteral Nutr. 1997; 21: 357-365.

24. Guarner F. Enteric Flora in Health and Disease. Digestión. 2006; 73: 5-12.

25. Miñana V. Probióticos, prebióticos y simbióticos. Pediatría integral. 2007; 11.

26. Ogawa T. Oral administration of Bifidobacterium long in a gastro-resistant seamless capsule decreases serum phosphate levels in patients receiving hemodialysis. Clin Kidney J. 2012; 5: 373-374.

27. Briskey D, Tucker P, Jhonson DW, Coombes JS. The role of the gastrointestinal tract and microbiota on uremic toxins and chronic kidney disease development. Clin Exp Nephro. 2017; 21: 7-15.

28. Evenepoel P. Uremic toxins originating from colonic microbial metabolism Kidney International. 2009; 76: S12-S19.

29. Wei M. Probiotic Bifidobacterium animalis subsp. lactic Bi-07 alleviates bacterial translocation and ameliorates microinflammation in experimenta uremia. Nephrology. 2014; 19: 500-506.

30. Koppe L. Probiotics and chronic kidney disease. Kidney International. 2015 88: 958-966.

31. Vaziri D, Yuan, Rahimi, Ni, Said, Subramanian S. Disintegration of the colonic epithelial tight junction in uremia: a likely cause of CKD-associated inflammation. Nephrol Dial Transplant. 2012; 27: 2693-2702.

32. LV, Linnane W, Gobe C. From the Gastrointestinal Tract (GIT) to the Kidneys: Live Bacterial Cultures (Probiotics) Mediating Reductions of Uremic Toxin Levels via Free Radical Signaling. Toxins. 2013; 5: 2042-2057.

33. de las Cagigas R, Ada L, Blanco Anesto J. PREBIÓTICOS Y PROBIÓTICOS UNA RELACIÓN BENEFICIOSA. Revista Cubana Aliment Nutr. 2002; 16 : 63-68.

34. Cross M, Ganner A, Teilab D, Fray L. Patterns of cytokine indution by gram positive and grand negative probiotic bacteria. FEMS Inmunonol Med Microbiol. 2004; 42: 173-180.

35. Young RJ HS. Probiotic use in children. J Pedriatr Health Care. 2003; 17 277-283.

36. González BE, Treviño M, Jiménez Z. Bacteriocinas de probióticos. 2003; 4.

37. Taki K, Takayama F, Niwa T. Beneficial effects of Bifidobacteria in a gastroresistant seamless capsule on hyperhomocysteinemia in hemodialysis patients. J Renal Nutr. 2005; 15: 77-80.
38. Chow K, Liu Z, Prakash S, Chang T. Free and microencapsulated Lactobacillus and effects of metabolic induction on urea removal. Artif Cells Blood Substit Immobil Biotechnol. 2003; 31: 425-434.

39. Ramezina A, Raj D. The Gut Microbiome, Kidney Disease, and Targeted. J Am Soc Nephrol. 2014; 1-14.

40. Younis K, Ahmad S, KJ. Health Benefits and Application of Prebiotics in Foods. Food Processing \& Technology. 2015; 1-7.

41. Vyas U, Ranganathan N. Probiotics, Prebiotics, and Synbiotics: Gut and Beyond. Gastroenterology Research and Practice. 2012; 1-17.

42. Zirker L. The Relationship between Gut Microbiota and CKD: Why Use Prebiotics in CKD Patients? Renal Nutrition Forum. 2014; 1-6.

43. Moura P. Development of prebiotic food products and health benefits. Food Science and Technology. 2015; 35: 1-8.

44. Aliasgharzadeh AKM, Mirtaheri E, Pourghassem Gargari B, Tavakoli F, Abbasalizad Farhangi $\mathrm{M}$, Babaei $\mathrm{H}$, et al. A Combination of Prebiotic Inulin and Oligofructose Improve Some of Cardiovascular Disease Risk Factors in Women with Type 2 Diabetes: A Randomized Controlled Clinical Trial. Adv Pharm Bull. 2015; 5: 507-514

45. Roberfroid B. Prebiotics and probiotics: are they functional foods? Am J Clin Nutr. 2000; 71: 1682S-1687S.

46. Stanton, Gardiner G, Meehan H, Collins K, Fitzgerald G, Brendan Lynch P, et al. Market potential for probiotics. The American Journal of Clinical Nutrition. 2001; 73: 476S-483S.

47. Miranda Alatriste V, Urbina Arronte, Gómez Espinosa, Espinosa Cuevas dlÁ Effect of probiotics on human blood urea levels in patients with chronic renal failure. Nutrición Hospitalaria. 2014; 29: 582-590.

48. Ranganathan N, Ranganathan P, Friedman E, Joseph A, Delano B, Goldfarb $D$, et al. Pilot Study of Probiotic Dietary Supplementation for Promoting Healthy Kidney Function in Patients with Chronic Kidney Disease. Adv ther. 2010; $27: 634-647$

49. Cruz-Mora J, Martínez-Hernandez E, Martín del Campo-López F, ViramontesHorner D, Vizmanos-Lamotte, Muñoz-Valle JF, et al. Effects of a Symbiotic on Gut Microbiota in Mexican Patients with End-Stage Renal Disease. Journal of Renal Nutrition. 2014; 24: 330-335.

50. Natarajan R, Pechenyak B, VU, Ranganathan P, Liang P, Mallapallil M, et al. Randomized Controlled Trial of Strain-Specific Probiotic Formulation (Renadyl) in Dialysis Patients. BioMed Research International. 2014.

51. Nakabayashi M, Nakamura K, Kawakami. Effects of synbiotic treatment on serum level of p-cresol in hemodialysis patients: a preliminary study. Nephrol Dial Transplant. 2010; 26: 1094-1098.

52. Salmean Y, Segal M, Langkamp-Henken B, Canales M, Zello G, Dahl W. Foods With Added Fiber Lower Serum Creatinine Levels in Patients With Chronic Kidney Disease. Journal of Renal Nutrition. 2013; 23: 29-32.
J Fam Med - Volume 4 Issue 5 - 2017

ISSN : 2380-0658 | www.austinpublishinggroup.com

Jiménez-Báez et al. (C) All rights are reserved
Citation: Cituk-Cutz GJ, Pech-Canul ER, Tuyub-Alonzo R, Jiménez-Báez MV, Ureña-Bogarín EL, SandovalJurado L, et al. Symbiotic Gels: Alternative in Renal Insufficiency. J Fam Med. 2017; 4(5): 1126 